\title{
Non-homologous End Joining Inhibitor SCR-7 to Exacerbate Low-dose Doxorubicin Cytotoxicity in HeLa Cells
}

\author{
Ajay Kumar, Devyani Bhatkar, Devashree Jahagirdar, Nilesh Kumar Sharma \\ Cancer and Translational Research Lab, Dr. D.Y Patil Biotechnology \& Bioinformatics Institute, Dr. D. Y. Patil Vidyapeeth, Pune, India
}

\begin{abstract}
Among the genotoxic drug regimens, doxorubicin (DOX) is known for its high-dose side effects in several carcinomas, including cervical cancer. This study reports on testing the combined use of a DOX genotoxic drug and SCR-7 non-homologous end joining (NHEJ) inhibitor for HeLa cells. An in vitro DNA damaging assay of DOX was performed on plasmid and genomic DNA substrate. In vitro cytotoxicity was investigated using trypan blue dye exclusion, DNA metabolizing, and propidium iodide-based flow cytometric assays. DOX (between 20-100 $\mu \mathrm{M}$ ) displayed clear DNA binding and interaction, such as the shearing and smearing of plasmid and genomic DNA. DNA metabolizing assay data indicate that HeLa lysate with DOX and SCR-7 treatment exhibited better in vitro plasmid DNA stability compared with DOX treatment alone. SCR-7 augmented the effects of low-dose DOX by demonstrating enhanced cell death from $15 \%$ to $50 \%$. The flow cytometric data also supported that the combination of SCR-7 with DOX lead to a $23 \%$ increase in propidium iodide-based HeLa staining, thus indicating enhanced death. In summary, the inhibition of NHEJ DNA repair pathway can potentiate low-dose DOX to produce appreciable cytotoxicity in HeLa cells.
\end{abstract}

(J Cancer Prev 2017;22:47-54)

Key Words: Carcinoma, Chemotherapy, DNA damage, DNA repair, Genomic instability

\section{INTRODUCTION}

The use of doxorubicin (DOX) has been frequently questioned due to observed high-dose-related side effects and drug resistance. ${ }^{1-3}$ The failure of DOX-based chemotherapy response is perceived as being due to the ability of carcinoma to repair genomic insults. Therefore, inhibiting the DNA damage response (DDR) pathway appears to be a suitable strategy to achieve better responsiveness in cancer treatment. ${ }^{1,2} \mathrm{~A}$ frontline drug, DOX, has been reported to cause toxicity due to the life-threatening cardiotoxicity and cancer therapeutic options have become dose-limiting. ${ }^{3-8}$

Several genotoxic drugs cause DNA damage, including alkylation, oxidation, single-strand breaks, and double-strand breaks (DSBs) in carcinoma. ${ }^{9-14}$ The DDR is defined as an inherent common feature in both normal and carcinoma in the response to genomic lesions and toxic stress. ${ }^{12-14}$ Both carcinoma and normal cells employ several DNA repair pathways, such as mismatch repair, nucleotide excision repair, base excision repair, homologous recombination, and non-homologous end joining (NHEJ). ${ }^{10-12}$ DNA DSB is defined as the principle cytotoxic lesion for ionizing radiation, but it can also be generated by genotoxic drugs. ${ }^{9-14}$ A type of DSB repair via the NHEJ pathway has been considered a potential therapeutic route because it inhibits key proteins responsible for genotoxic drug resistance. There are notable attempts to test certain inhibitory drugs, such as KU-55933, SCR-7, SCR-17, and L189, against proteins in the DSB repair pathway. ${ }^{15-22}$ These inhibitors are suggested to work synergistically with genotoxic drugs by several molecular mechanisms. ${ }^{15-22}$ Here, we provide evidence of dose-dependent

Received February 7, 2017, Revised March 1, 2017, Accepted March 6, 2017

Correspondence to: Nilesh Kumar Sharma

Cancer and Translation Research Group, Department of Biotechnology, Dr. D. Y. Patil Biotechnology \& Bioinformatics Institute, Dr. D. Y Patil Vidyapeeth Pune, Pune, MH 411033, India

Tel: +91-7219269540, Fax: +91-2067919444, E-mail: nilesh.sharma@dpu.edu.in, ORCID: Nilesh Kumar Sharma, http://orcid.org/0000-0002-8774-3020

Copyright (C) 2017 Korean Society of Cancer Prevention

(c) This is an Open Access article distributed under the terms of the Creative Commons Attribution Non-Commercial License (http://creativecommons.org/licenses/by-nc/4.0) which permits unrestricted non-commercial use, distribution, and reproduction in any medium, provided the original work is properly cited. 
DNA substrate damage and shearing by DOX. At present, the findings suggest that low-dose DOX could be combined with SCR-7, a NHEJ inhibitor, to produce appreciable cytotoxicity in HeLa cells.

\section{MATERIALS AND METHODS}

\section{Reagents}

DOX (Catalogue Number-15007) and SCR-7 (Catalogue Number-18015) were purchased from Cayman Chemical (Ann Arbor, MI, USA). All other cell culture media, reagents, serum, chemicals, and plasmid pBR322 were purchased from HiMedia India Pvt. Ltd. (Mumbai, India).

2. Culture, maintenance, and cryopreservation of HeLa cells

HeLa cells were purchased from NCCS (Pune, India). Frozen cells were thawed at $37^{\circ} \mathrm{C}$ and grown in Dullbecco's Modified Eagles Medium (DMEM) with 10\% FBS. Cell culture media was supplemented with antibiotic solution containing 10,000 units of penicillin and $10 \mathrm{mg}$ of streptomycin with $5.0 \% \mathrm{CO}_{2}$.

\section{In vitro plasmid DNA and genomic DNA break assay}

To assess the DNA break ability of DOX, $1 \mu \mathrm{L}$ of pBR322 (100 $\mathrm{ng} / \mu \mathrm{L}$ ) and $1 \mu \mathrm{g}$ of genomic DNA (bacterial and animal cells) were mixed with $2 \mu \mathrm{L}$ of TAE buffer (Tri-acetate/EDTA $10 \mathrm{mM}, \mathrm{pH}$ 7.4). DOX, ranging from 20 to $100 \mu \mathrm{M}$, was added to the reaction mixture. The final volume of each reaction mixture was brought to $25 \mu \mathrm{L}$ with the addition of nuclease free water. Reaction mixtures were incubated for 24 hours at $37^{\circ} \mathrm{C}$. Following incubation, $4 \mu \mathrm{L}$ of DNA loading dye was added to the incubated mixture. Finally, $20 \mu \mathrm{L}$ of DNA sample was loaded on a $1 \%$ (w/v) agarose gel. Electrophoresis was conducted at 100 volts in tris-acetate-EDTA $\cdot \mathrm{Na}_{2}$ (TAE) buffer (0.04 M tris-acetate and 1 mM EDTA, pH 7.4) using a Horizon 58 (Life Technologies, Carlsbad, CA, USA). DNA bands were visualized with a Bio-Rad Gel Doc $^{\mathrm{TM}}$ EZ imager.

\section{Preparation of doxorubicin/SCR-7}

DOX was initially prepared as a stock solution by dissolving 5 $\mathrm{mg}$ in $500 \mu \mathrm{L}$ of dimethyl sulfoxide (DMSO) and stored at $-20^{\circ} \mathrm{C}$. A final working concentration of $25 \mathrm{nM}$ was used in the cell cytotoxicity assay. SCR-7 inhibitor was first prepared at a stock concentration of $29.8 \mathrm{mM}$ by dissolving $5 \mathrm{mg}$ of powder in $500 \mu \mathrm{L}$ of DMSO, and it was stored at $-20^{\circ} \mathrm{C}$. The final working concentration was used at $50 \mu \mathrm{M}$ in various cell cytotoxicity assays.

\section{Trypan blue dye exclusion assay}

HeLa cells at $80 \%$ to $90 \%$ confluency were harvested and plated on a six-well plate at $2 \times 10^{5}$ cells per well. The culture media volume was kept at $2 \mathrm{~mL}$, and cells were allowed to grow for the next 16 to 18 hours. On the next day, the plated HeLa cells were organized in triplicate for the following treatment conditions: DMSO control, DOX (25 nM), and DOX (25 nM) + SCR-7 (50 $\mu \mathrm{M})$ in a final volume of $2 \mathrm{~mL}$ of complete DMEM media. The combined drug and inhibitor treatment was allowed to incubate for 48 hours at $37^{\circ} \mathrm{C}$. After incubation, media were removed and any floating cells were recovered in the aspirated media. Then, wells were washed with PBS and treated with 0.3 to $0.5 \mathrm{~mL}$ of $0.25 \%$ trypsin/EDTA for 2 to 3 minutes at $37^{\circ} \mathrm{C}$. Subsequently, 2 $\mathrm{mL}$ of media was added to inactivate trypsin, and the samples were centrifuged for 2 minutes at 2,000 rpm. Then, cell pellets were mixed with an appropriate volume of complete cell culture media. Next, $10 \mu \mathrm{L}$ of trypan blue dye was mixed with $10 \mu \mathrm{L}$ of the cell suspension and the cells were counted using a standard hemocytometer-based cell counting method.

\section{DNA metabolizing activity of HeLa cell lysates}

The DNA metabolizing assay reaction included plasmid pBR322 and DOX $(30 \mu \mathrm{M})$ as mentioned for the DNA damaging activity assay. Then, reaction tubes were added with whole HeLa cell protein lysates prepared from the following treatment conditions: DMSO control, DOX (25 nM), and DOX (25 nM) + SCR-7 $(50 \mu \mathrm{M})$. The DNA metabolizing activity was performed at $37^{\circ} \mathrm{C}$ for 24 hours. Next, DNA gel electrophoresis stained with ethidium bromide was performed according to a standard protocol to assess the DNA shearing or stabilization activity.

\section{Flow cytometric analysis}

HeLa cells $\left(12 \times 10^{5}\right.$ cells/dish) were grown in $35-\mathrm{mm}^{2}$ culture dishes with three replicates. After 16 to 18 hours, cells were treated with DMSO control, DOX (25 nM), DOX (25 nM) + SCR-7 $(50 \mu \mathrm{M})$, and negative control of cisplatin alone $(33 \mu \mathrm{M})$. At the end of 48 hours, $2 \mathrm{~mL}$ of $500 \mu \mathrm{L}$ Trypsin-EDTA (Gibco; Invitrogen, Carlsbad, CA, USA) was added to each dish for 3 to 4 minutes. Next, the harvested cell suspension was centrifuged at 6,000 $\times g$ for 3 minutes and the pellet was washed twice with Hank's buffered salt solution. Further, $10 \mu \mathrm{L}$ of propidium iodide (PI) $(50$ $\mathrm{mg} / \mathrm{mL}$ ) was added to cell pellets at a final concentration of 10 $\mathrm{mg} / \mathrm{mL}$. After PI addition, the samples were incubated for 30 minutes and pelleted. Then, the pellet was again washed twice with PBS. In the next step, the pellet was suspended in BD 
staining buffer and analyzed using a flow cytometer (BD FACSJazz; BD Biosciences, San Jose, CA, USA). A minimum of 10,000 events was collected and analyzed using a 488-nm laser and $610 \mathrm{LP}, 616 / 23 \mathrm{BP}$ emission filters. Values were represented as a percentage of control.

\section{Statistical analysis}

The experiments were independently conducted three times. The results are expressed as the mean \pm SD. Data from the different assays were statistically in Microsoft Excel statistical package (Microsoft, Redmond, WA, USA) using the $t$-test. Statistical significance was acceptable at a level of $P<0.05$.

\section{RESULTS AND DISCUSSION}

DOX (also called Adriamycin) belongs to the anthracycline class of compounds. DOX has great efficacy in both solid and liquid tumors. The recent emergence of drug resistance and the potential side effect of cardiotoxicity represent major limitations for successful cancer treatment. ${ }^{46,23,24}$ Despite its extensive use, the molecular mechanism(s) by which DOX causes cell death or cardiotoxicity remains unclear. Several models have been proposed for DOX-mediated cell death, including topoisomerase II (TOP2) poisoning, DNA adduct formation, and oxidative stress. ${ }^{6-8}$ Basically, the mechanisms of DNA TOP2 and DOX interaction involve a covalent DSB intermediate. This enzyme is coupled to DNA via a 5'-phosphotyrosyl bond and a transiently stabilized $\mathrm{DSB}^{4.8}$

DOX is reported to interact directly with nucleotides, polynucleotides, RNA, calf thymus DNA, and plasmid DNA, which is considered in addition to its action as a Topo II enzyme poison. An earlier report has demonstrated that DOX binds and intercalates with DNA substrate and a precisely guanine ring structure. ${ }^{48,23,24}$ However, with supercoiled DNA and nucleosomes, DOX destabilizes the helix at a very low concentration. At the same time, the findings indicate that HeLa cells may show less vulnerability to these drugs by modulating the DSB response settings, leading to a lethal double strand break. In addition to DOX, another anthraquinone drug class, dynemicin, demonstrates DNA interaction, and cleavage activity. ${ }^{24}$

The discernible abilities of any genotoxic drugs/inhibitors are frequently tested by substrate-based cleaving, nicking, or damaging potential at $37^{\circ} \mathrm{C}$ for 24 hours. Ethidium bromide-stained DNA agarose revealed DNA damage and smearing (Fig. 1A). Data indicated the absence of DNA damage with $20 \mu \mathrm{M}$ DOX. However, both plasmid DNA FORM I and FORM II showed degradation and smearing with increased concentrations up to $100 \mu \mathrm{M}$. Surprisingly, degraded DNA was observed in the opposite direction for FORM I and FORM II plasmid DNA. The damaging action of DOX on DNA substrate was extended to bacterial and HeLa genomic DNA. An agarose DNA-stained photograph was presented to depict the DNA damage effects of DOX (Fig. 1B). It showed that $100 \mu \mathrm{M}$ DOX completely degraded genomic DNA substrate, which appeared in the form of damaged or smeared DNA behind the loading well position. The present data suggest that DOX, ranging from 20 to $100 \mu \mathrm{M}$, interacted with and degraded genomic DNA. Genomic DNA degradation due to DOX was consistent with plasmid DNA degradation. The current findings support an earlier view of DOX action inside cells as a direct genome-shearing agent beyond acting as a TOP2 enzyme poison
A

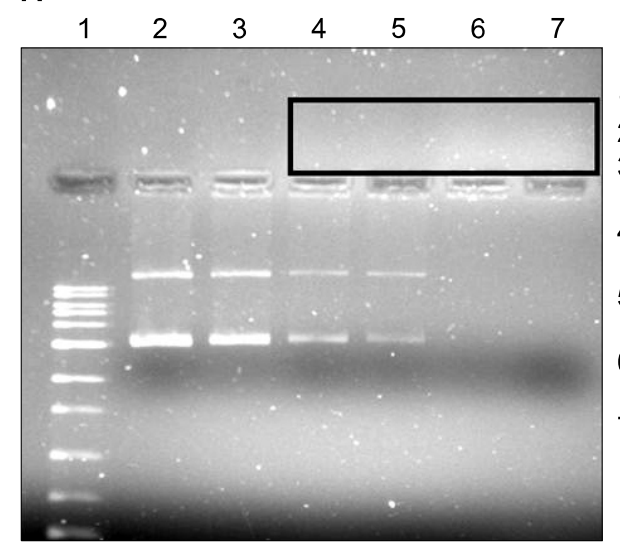

1. DNA ladder

2. Buffer control (buffer)

3. $\operatorname{DOX}(20 \mu \mathrm{M})+$ plasmid pBR322

4. $\operatorname{DOX}(40 \mu \mathrm{M})+$ plasmid

5. DOX $(50 \mu \mathrm{M})+$ plasmid

6. DOX $(80 \mu \mathrm{M})+$ plasmid

7. $\operatorname{DOX}(100 \mu \mathrm{M})+$ plasmid
B

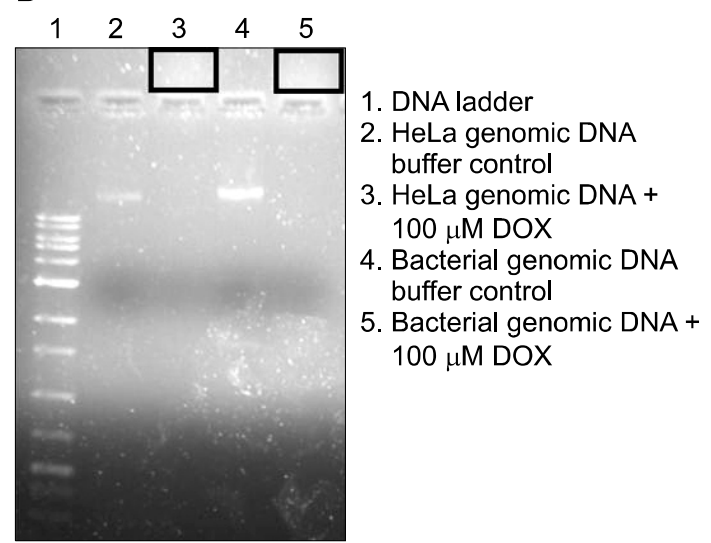

Figure 1. In vitro DNA damage activity of doxorubicin (DOX). (A) One microliter of pBR322 (100 ng/ $\mu \mathrm{L})$ or (B) $1 \mu \mathrm{g}$ of genomic DNA (bacterial and animal cells) in $2 \mu \mathrm{L}$ of TAE buffer was exposed to DOX, ranging from 20 to $100 \mu \mathrm{M}$, which was followed by the addition of $25 \mu \mathrm{L}$ of nuclease free water. Reaction mixtures were incubated for 24 hours at $37^{\circ} \mathrm{C}$. The DNA sample was loaded on a $1 \%$ (w/v) agarose gel. DNA bands were visualized with a Bio-Rad Gel Doc ${ }^{\mathrm{TM}} \mathrm{EZ}$ imager. Each experiment was independently conducted three times. 
to achieve carcinoma toxicity.

The trypan blue dye exclusion assay is a widely accepted assay to understand the anti-cancer activity of drugs/inhibitors, including both anti-proliferative and cytotoxic activity. ${ }^{25,26}$ Photomicrograph data were obtained from microscopy at the end of experiment without the addition of trypan blue dye (Fig. 2A). These photomicrographs clearly demonstrate that a low-dose DOX concentration at $25 \mathrm{nM}$ could block proliferation compared to the normal DMSO control. To our surprise, there are clear indications that NHEJ inhibitor, SCR-7, had almost identical anti-proliferative effects in HeLa cells during combined treatment of DOX plus SCR-7. Such observations may be due to the abilities of HeLa cells to strategically use DNA repair protein players to counter the effects of both DOX and DNA repair protein inhibitors.

Further, the treatment conditions of drugs/inhibitors as mentioned above were used in 96-well plate assays in which trypan blue dye was directly added and microscopy photographs were taken (Fig. 2C). These data demonstrated that a low dose of DOX produced significant arrest in proliferation and slight cytotoxicity but that the level of dead cells was not significant. Additionally, SCR-7 inhibitor appears to significantly potentiate the DOX drug effects by eliciting cell death. These data are also reinforced by the above six-well plate photomicrograph microscope study.

In addition to microscopy data, the trypan blue exclusion dye method provided us a total cell count and viable and dead cell estimation. The total cell count data were plotted in the form of a bar graph and are presented in Figure 2B for the total cell count in each treatment condition. The results are presented in the form of plotted data as a percentage of trypan blue dye-stained dead cells normalized to DMSO control (Fig. 2D). The data demonstrated that SCR-7 could play a role in potentiating DOX low-dose effects to enhance cell death. In Figure 2B, the data indicate, based on the total cell count, that DOX alone reduced the total cell count, which is not significantly different from DOX plus SCR-7. In contrast, Figure 2D demonstrates the cell viability using the trypan blue exclusion assay, wherein the data are shown as the percentage of dead cells compared to DMSO control. DOX alone causes some cell death, but the combination of DOX with SCR-7 increased cell death.
A

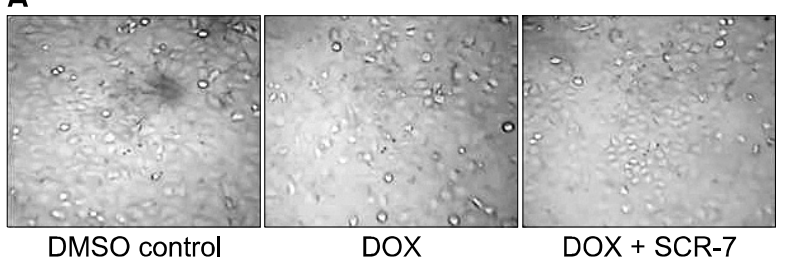

B

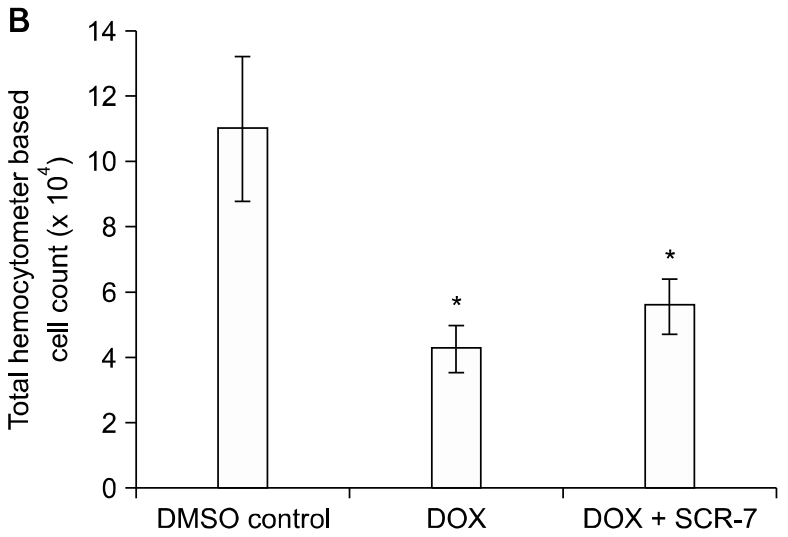

C

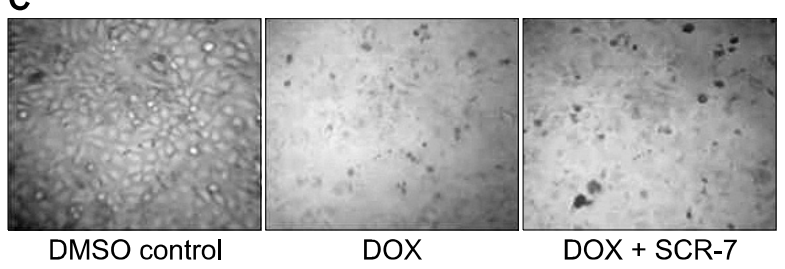

D

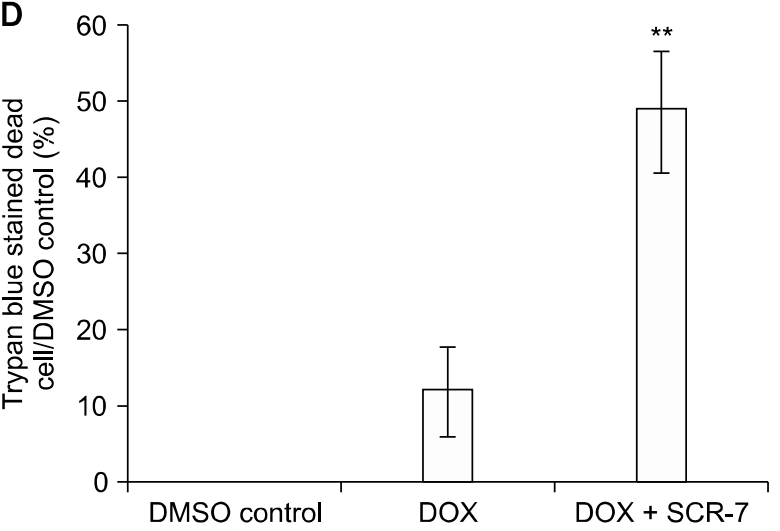

Figure 2. Cytotoxic effects of DOX alone or in combination with SCR-7 in HeLa cells. HeLa cells $\left(2 \times 10^{5}\right.$ cells/well $)$ were allowed to grow for 16 to 18 hours and were then treated with dimethyl sulfoxide (DMSO) control, DOX (25 nM), DOX (25 nM) + SCR-7 (50 $\mu \mathrm{M})$ for 48 hours. The cells were collected, washed, and treated with 0.25\% trypsin/EDTA. Cell counting with hemocytometer was performed in cells treated with trypan blue dye. (A) Before treatment with trypan blue dye, a microscope photograph was captured using a light inverted microscope $(10 X)$ and (B) Trypan blue dye exclusion-based hemocytometer counting was performed to determine the total HeLa cell number. (C) The microscopy photograph was taken at $10 \times$ after staining with trypan blue dye. (D) Trypan blue stained cells were counted with a hemocytometer to assess the presence of dead cells due to drug/inhibitor treatment. Data are presented as the percentage of trypan blue stained dead cells in each treatment condition over DMSO treatment and are represented as the mean \pm SD. Each experiment was independently conducted three times. ${ }^{*} P<0.05$ and $* * P<0.01$, significantly different from DMSO control. 
Other cell cytotoxicity data indicate that SCR-7 may interfere with cancer growth and proliferation by blocking the sealing of double strand breaks. ${ }^{22-28}$ Additionally, SCR-7 and other small-molecule inhibitors to DSB repair have been reported as viable options in primary and adjuvant chemotherapies for several cancer types. There are reports on cardiac glycosides acting as potential inhibitors of DNA DSB repair by phosphorylating DNA damage checkpoint protein 1 (phospho-MDC1) or E3 ubiquitin-protein ligase ring finger protein $8(\mathrm{RNF} 8) .{ }^{20}$ In a recent paper, Wang et al. ${ }^{27}$ reported that inhibition of CtIP (RBBP8), a DSB repair protein, sensitizes breast carcinoma to PARP inhibitor olaparib (AZD2281) or veliparib (ABT-888) therapy. Such findings introduce prospects to select options as DNA repair protein inhibitors by supplementing the existing regimen of genotoxic drugs.

Recent findings indicate that caffeine can lead to proteasomal degradation of Sae2 nuclease and Dna2 nuclease in DNA resection. Further, the data suggest the use of caffeine as a DNA damage-sensitizing agent in cancer. ${ }^{28}$ Recently, small-molecule inhibitors of ribonucleotide reductase have also been linked to the increased sensitivity of BRCA wild-type ovarian carcinoma to PARP inhibitor olaparib and etoposide. ${ }^{25}$

DNA metabolizing activity evaluations of HeLa whole cell lysates were performed using the plasmid DNA damage assay with a DNA damage drug, DOX. The ethidium bromide-stained DNA agarose gel is presented in Figure 3. The data indicate that HeLa cells treated with SCR-7 and DOX possessed better DNA stabilizing effects compared to DNA degradation in HeLa lysates treated with DOX alone. The current observation appears to be

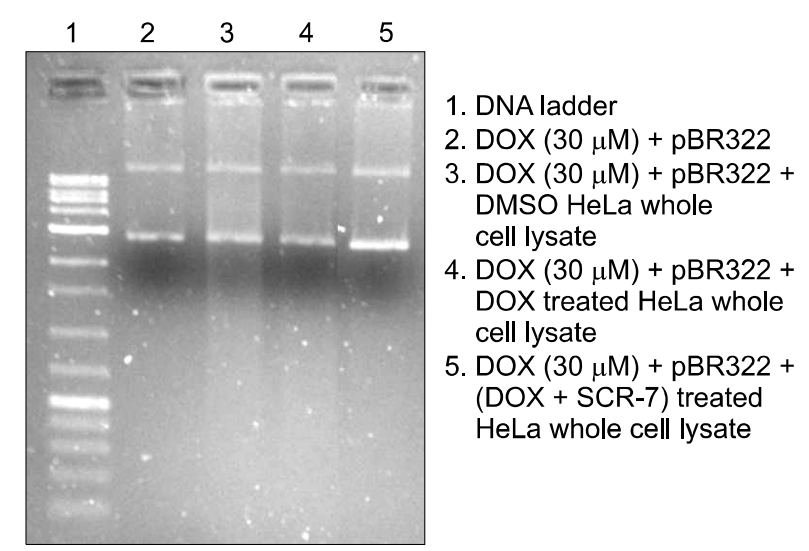

Figure 3. DNA metabolizing activity of HeLa cell lysates with or without drug/inhibitor treatment. pBR322 plasmid DNA was treated with HeLa cell lysates extracted from cytotoxicity assay for dimethyl sulfoxide (DMSO) control, doxorubicin (DOX) $(25 \mathrm{nM})$, DOX (25 nM) + SCR-7 $(50 \mu \mathrm{M})$ as mentioned in the Materials and Methods section. The gel photograph is a representative of agarose gel electrophoresis. supported by earlier data based on the concomitant use of several genotoxic drugs and DNA repair protein for achieving better results in cancer chemotherapy. ${ }^{10,15-22}$

Flow cytometry analysis of the effect of DOX and a SCR-7 inhibitor in HeLa cells was performed using a PI-based cell viability assay. Raw data on PI-stained and unstained HeLa cells are presented in Figure 4A-4D. Further, the results are presented as a bar graph of the percentage of PI-stained HeLa cells normalized by DMSO control cells (Fig. 4E). The data indicate the absence of PI-stained HeLa cells with a low dose of DOX. However, SCR-7 combined with DOX produced a very significant level of PI-stained HeLa cells, indicating the presence of cell death. In the flow cytometry assay, additional negative control with $33 \mu \mathrm{M}$ cisplatin is used in HeLa cells and lacked a PI-stained cell population. Thus, the flow cytometry data suggest that SCR-7 can work as a potentiating inhibitor with low-dose DOX in less responsive carcinoma. In Figure $4 \mathrm{E}$, there is not a significant difference between the DMSO control and DOX-treated HeLa cells with respect to the percentage of PI-stained dead cells. These observations suggest that the origin of inherent cellular mechanisms in HeLa cells involves compromising the DSB repair system and activating compensatory DNA repair systems. Recently, the combined use of DOX and simvastatin has been shown to increase cancer cell death. ${ }^{29}$ Therefore, an option for decreasing the drug concentration and supplementing treatment with the potential inhibitors, such as double strand break repair protein inhibitors, has been explored to test the synergistic or antagonistic effects in cancer toxicity. Genotoxic inflicted DNA damage is reported to persist in carcinoma. In another way, the cellular machinery is spurred to action by influencing a defined set of DNA repair players. Here, the evidence supports that individual carcinoma patients utilize DNA repair systems to thwart drug effects. However, numerous experimental findings indicate that DNA repair protein inhibitors could potentiate the effects of low-dose DOX via apoptotic cell death. ${ }^{22-29}$ The results in this study seem to agree with earlier findings of high expression of DNA ligase IV in HeLa and other carcinoma cell lines. $^{22-29}$

To summarize the present findings, the data presented here suggest that SCR-7, a NHEJ repair inhibitor, could push HeLa cells towards cell death in the presence of low-dose DOX. Hence, this finding supports that the side effects of a genotoxic drug, DOX, can be reduced by the concomitant addition of a DNA repair protein inhibitor, SCR-7, and many other potential molecular inhibitors. Further investigation is needed to dissect the molecular basis of the observed synergistic effects between DOX and 
A

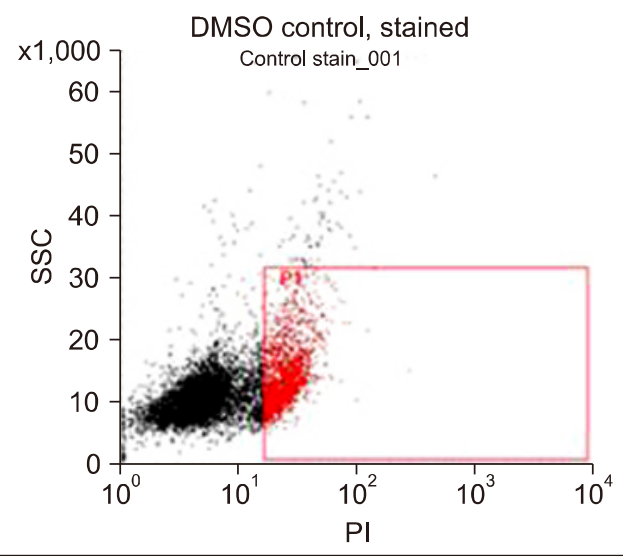

\begin{tabular}{|lrrr|}
\hline \multicolumn{2}{l}{ Populations: control stain_001 } & & \\
Populations & Event & Total (\%) & Patient (\%) \\
All events & 10.000 & $100.00 \%$ & $\# \#$ \\
P1 & 2.288 & $22.88 \%$ & $22.88 \%$ \\
\hline
\end{tabular}

C

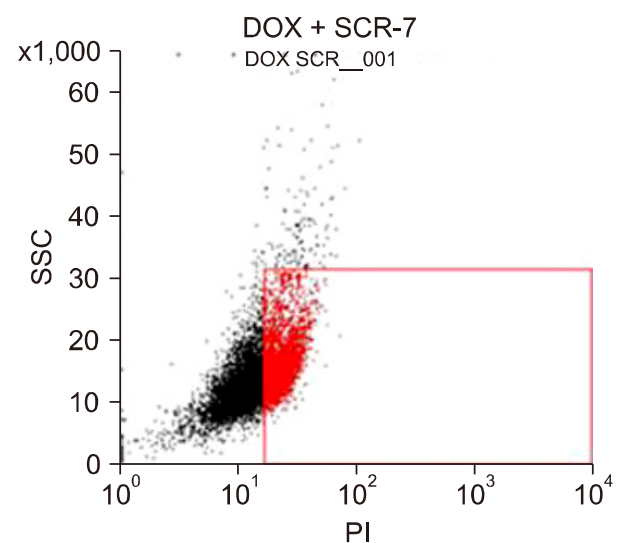

\begin{tabular}{|lrrrrr|}
\hline Statistics: DOX SCR_001 & & & PI & SSC \\
Populations & Event & Total (\%) & Patient (\%) & Mean & Mean \\
All events & 10.000 & $100.00 \%$ & $\# \#$ & 16 & 14.032 \\
P1 & 4.330 & $43.30 \%$ & $43.30 \%$ & 23 & 15.747 \\
\hline
\end{tabular}

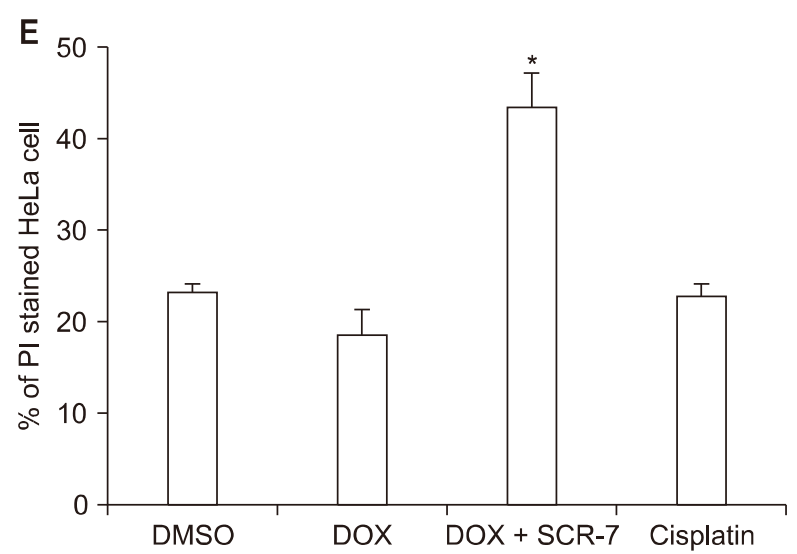

B

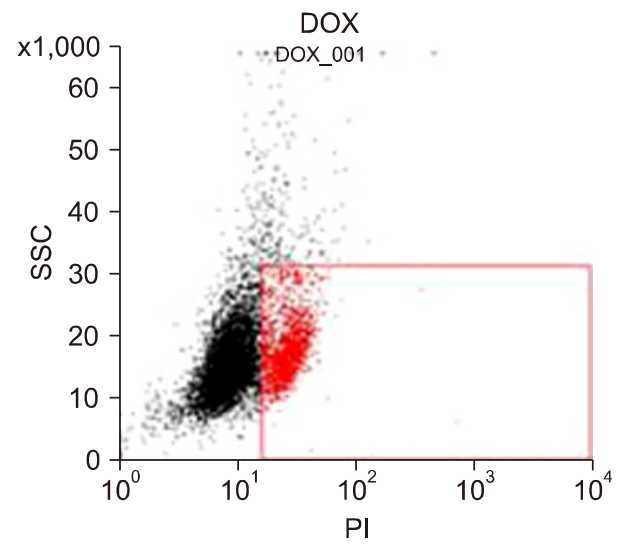

\begin{tabular}{|lrrrrr|}
\hline Statistics: DOX_001 & & & & PI & SSC \\
Populations & Event & Total (\%) & Patient (\%) & Mean & Mean \\
All events & 10.000 & $100.00 \%$ & $\# \#$ & 13 & 16.011 \\
P1 & 1.827 & $18.27 \%$ & $18.27 \%$ & 28 & 18.104 \\
\hline
\end{tabular}

D

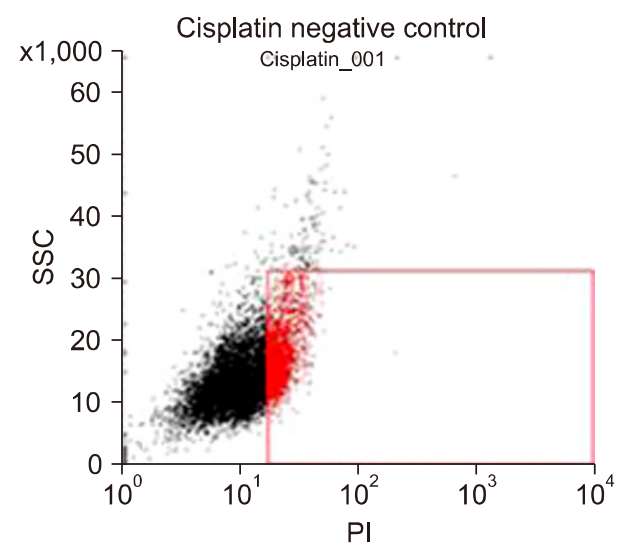

\begin{tabular}{|lrrrrr|}
\hline \multicolumn{2}{|c}{ Statistics: cisplatin_001 } & & & PI & SSC \\
\multicolumn{1}{c}{ Populations } & Event & Total (\%) & Patient (\%) & Mean & Mean \\
\hline All events & 10.000 & $100.00 \%$ & \#\# & 12 & 14.108 \\
P1 & 2.261 & $22.61 \%$ & $22.61 \%$ & 22 & 17.359 \\
\hline
\end{tabular}

Figure 4. The flow cytometric analysis for propidium iodide-based cell viability determination of HeLa cells. HeLa cells $\left(2 \times 10^{5}\right.$ cells/dish $)$ were treated with (A) dimethyl sulfoxide (DMSO), (B) doxorubicin (DOX) (25 nM), (C) DOX (25 nM) + SCR-7 $(50 \mu \mathrm{M})$ ) or (D) cisplatin (33 $\mu \mathrm{M})$ for 48 hours and stained with propidium iodide (PI). PI-stained cells were suspended in BD staining buffer and analyzed on a flow cytometer. A minimum of 10,000 events were collected and analyzed using a $488 \mathrm{~nm}$ laser and 610 LP, 616/23 BP emission filters. Data is presented in scattered plot with side-scattered light (SSC) on Y-axis and PI-stained HeLa cells on X-axis. (E) Data were represented as a percentage of control and the mean $\pm \mathrm{SD}$. $* P<0.05$, significantly different from DMSO control. 
SCR-7 in HeLa cells and may be extended to other carcinomas.

In conclusion, DOX at a low dose of $25 \mathrm{nM}$ has a lower response in HeLa cells, but the combination of DOX and a NHEJ inhibitor, SCR-7, can potentiate HeLa cell death. These findings may provide options for the synergistic use of SCR-7 with low-dose DOX to avoid harmful effects and achieve better responsiveness in HeLa cells and other carcinomas.

\section{ACKNOWLEDGMENTS}

The authors would like to thank the Cancer Biology Research Group for their constant support and motivation and our host institute Dr. D. Y. Patil Biotechnology \& Bioinformatics Institute, Dr. D. Y Patil Vidyapeeth, Pune for providing resources. The authors acknowledge the financial support from DST, SERB, New Delhi and DPU, Pune. The authors also acknowledge CRF at DPU, Pune facility for Flow cytometer facility.

\section{CONFLICTS OF INTEREST}

No potential conflicts of interest were disclosed.

\section{REFERENCES}

1. Schnitt SJ. Classification and prognosis of invasive breast cancer: from morphology to molecular taxonomy. Mod Pathol 2010;23 Suppl 2:S60-4

2. Velic D, Couturier AM, Ferreira MT, Rodrigue A, Poirier GG, Fleury F, et al. DNA damage signalling and repair inhibitors: The long-sought-after Achilles' heel of Cancer. Biomolecules 2015;5: 3204-59.

3. Duran GE, Lau DH, Lewis AD, Kühl JS, Bämmler TK, Sikic BI. Differential single- versus double-strand DNA breakage produced by doxorubicin and its morpholinyl analogues. Cancer Chemother Pharmacol 1996;38:210-6.

4. Faversani A, Vaira V, Moro GP, Tosi D, Lopergolo A, Schultz DC, et al. Survivin family proteins as novel molecular determinants of doxorubicin resistance in organotypic human breast tumors. Breast Cancer Res 2014:16:R55.

5. Yang F, Kemp CJ, Henikoff S. Anthracyclines induce double-strand DNA breaks at active gene promoters. Mutat Res 2015;773:9-15.

6. Guerreiro PS, Fernandes AS, Costa JG, Castro M, Miranda JP, Oliveira NG. Differential effects of methoxyamine on doxorubicin cytotoxicity and genotoxicity in MDA-MB-231 human breast cancer cells. Mutat Res 2013;757:140-7.

7. Pérez-Arnaiz C, Busto N, Leal JM, García B. New insights into the mechanism of the DNA/doxorubicin interaction. J Phys Chem B 2014;118:1288-95.

8. El-Awady RA, Semreen MH, Saber-Ayad MM, Cyprian F, Menon V, Al-Tel TH. Modulation of DNA damage response and induction of apoptosis mediates synergism between doxorubicin and a new imidazopyridine derivative in breast and lung cancer cells. DNA Repair (Amst) 2016;37:1-11.

9. Kumar A, Purohit S, Sharma NK. Aberrant DNA double-strand break repair threads in breast carcinoma: orchestrating genomic insult survival. J Cancer Prev 2016;21:227-34.

10. Puigvert JC, Sanjiv K, Helleday T. Targeting DNA repair, DNA metabolism and replication stress as anti-cancer strategies. FEBS J 2016:283:232-45.

11. Srivastava M, Raghavan SC. DNA double-strand break repair inhibitors as cancer therapeutics. Chem Biol 2015:22:17-29.

12. Bhatkar D, Kumar A, Jahagirdar D, Purohit S, Sharma NK. ATM kinase inhibitor KU-55933 contribution in cisplatin mediated HeLa proliferation. Int J Pharmacol Toxicol 2016;4:201-7.

13. Ceccaldi R, Rondinelli B, D'Andrea AD. Repair pathway choices and consequences at the double-strand break. Trends Cell Biol 2016:26:52-64.

14. Weterings E, Gallegos AC, Dominick LN, Cooke LS, Bartels TN, Vagner J, et al. A novel small molecule inhibitor of the DNA repair protein Ku70/80. DNA Repair (Amst) 2016;43:98-106.

15. Hong KJ, Hsu MC, Hung WC. RECK impedes DNA repair by inhibiting the erbB/JAB1/Rad51 signaling axis and enhances chemosensitivity of breast cancer cells. Am J Cancer Res 2015:5:2422-30.

16. Huang F, Goyal N, Sullivan K, Hanamshet K, Patel M, Mazina OM, et al. Targeting BRCA1- and BRCA2-deficient cells with RAD52 small molecule inhibitors. Nucleic Acids Res 2016;44:4189-99.

17. Rajamanickam S, Panneerdoss S, Gorthi A, Timilsina S, Onyeagucha B, Kovalskyy D, et al. Inhibition of FoxM1-mediated DNA repair by imipramine blue suppresses breast cancer growth and metastasis. Clin Cancer Res 2016:22:3524-36.

18. Chen X, Zhong S, Zhu X, Dziegielewska B, Ellenberger T, Wilson GM, et al. Rational design of human DNA ligase inhibitors that target cellular DNA replication and repair. Cancer Res 2008;68: 3169-77.

19. Srivastava M, Nambiar M, Sharma S, Karki SS, Goldsmith G, Hegde $\mathrm{M}$, et al. An inhibitor of nonhomologous end-joining abrogates double-strand break repair and impedes cancer progression. Cell 2012;151:1474-87.

20. Surovtseva $Y V$, Jairam V, Salem AF, Sundaram RK, Bindra RS, Herzon SB. Characterization of cardiac glycoside natural products as potent inhibitors of DNA double-strand break repair by a whole-cell double immunofluorescence assay. J Am Chem Soc 2016;138:3844-55.

21. Pandey M, Kumar S, Goldsmith G, Srivastava M, Elango S, Shameem M, et al. Identification and characterization of novel ligase I inhibitors. Mol Carcinog 2017:56:550-66.

22. Hickson I, Zhao Y, Richardson CJ, Green SJ, Martin NM, Orr AI, et al. Identification and characterization of a novel and specific inhibitor of the ataxia-telangiectasia mutated kinase ATM. Cancer Res 2004;64:9152-9.

23. Nayak PG, Paul P, Bansal P, Kutty NG, Pai KS. Sesamol prevents doxorubicin-induced oxidative damage and toxicity on H9c2 cardiomyoblasts. J Pharm Pharmacol 2013;65:1083-93.

24. Kusakabe T, Maekawa K, Ichikawa A, Uesugi M, Sugiura $Y$. Conformation-selective DNA strand breaks by dynemicin: a molecular wedge into flexible regions of DNA. Biochemistry 1993; 32:11669-75.

25. Strober W. Trypan blue exclusion test of cell viability. Curr Protoc Immunol 2001. doi: 10.1002/ 0471142735.ima03bs21. 
26. Louis KS, Siegel AC. Cell viability analysis using trypan blue: manualand automated methods. In: Stoddart MJ, ed. Mammalian Cell Viability: Methods and Protocols. Methods in Molecular Biology. Vol. 740. New York, Humana Press/Springer, 2011.

27. Wang J, Ding Q, Fujimori H, Motegi A, Miki Y, Masutani M. Loss of CtIP disturbs homologous recombination repair and sensitizes breast cancer cells to PARP inhibitors. Oncotarget 2016; 7:7701-14.
28. Tsabar M, Eapen VV, Mason JM, Memisoglu G, Waterman DP, Long MJ, et al. Caffeine impairs resection during DNA break repair by reducing the levels of nucleases Sae2 and Dna2. Nucleic Acids Res 2015:43:6889-901

29. Sadeghi-Aliabadi H, Minaiyan M, Dabestan A. Cytotoxic evaluation of doxorubicin in combination with simvastatin against human cancer cells. Res Pharm Sci 2010;5:127-33. 